\title{
Light-Induced Lipid Peroxidation in Isolated Chloroplasts and Role of $\alpha$-Tocopherol
}

\author{
Ryo YamaUCHI* and Setsuro MatSUSHITA \\ Research Institute for Food Science, Kyoto University, Kyoto \\ Received May 23, 1979
}

\begin{abstract}
Lipid peroxidation in isolated chloroplasts illuminated by visible light and the role of $\alpha$ tocopherol in chloroplasts were studied. The TBA reactants and fluorescent products derived from lipid peroxidation were formed by illumination. Peroxidation was inhibited by free radical scavengers and ${ }^{1} \mathrm{O}_{2}$ quenchers. Hydroxy methyl octadecanoates, which were the reduced and hydrogenated products of lipid hydroperoxides, were detected. Among them, 10and 15-hydroxy methyl octadecanoates were generated from ${ }^{1} \mathrm{O}_{2}$ oxidation. On the other hand, lipid hydroperoxides did not accumulate in this peroxidation process. The amount of $\alpha$ tocopherol in the chloroplasts decreased with lipid peroxidation, and $\alpha$-tocopheryl quinone was produced. The results indicate that $\alpha$-tocopherol acts as a free radical scavenger for photooxidation of chloroplasts.
\end{abstract}

Biological membranes are subjected to lipid peroxidation which leads to structural damage and to the disruption of cell integrity. Lipid peroxidation has been shown to be initiated by singlet molecular oxygen $\left({ }^{1} \mathrm{O}_{2}\right)$, which was generated photochemically or enzymatically. ${ }^{1 \sim 3\}}$ In plants, chloroplasts contain a large amount of chlorophyll which acts as a sensitizer in the photooxidation of lipids. ${ }^{45}$ Chloroplasts also contain phospholipids and glycolipids as constituents of the membrane structure. ${ }^{6,7)}$ Most of the lipids generally consist of polyunsaturated fatty acids, and therefore they undergo destructive damages from lipid peroxidation. It has been reported that isolated chloroplasts upon illumination could undergo destructive peroxidation initiated when light was absorbed by chlorophyll and that ${ }^{1} \mathrm{O}_{2}$ probably played an important role in photoinactivation and photodestruction of chloroplasts. $^{8,9)} \quad \alpha$-Tocopherol is located mainly in the chloroplasts of plant cells. ${ }^{10}$ Since tocopherols have been considered to function in biological systems as a free radical scavenger ${ }^{11,12)}$ or a ${ }^{1} \mathrm{O}_{2}$ quencher ${ }^{13,14)}$ for lipid peroxidation, $\alpha$-tocopherol in the chloroplasts may protect the structures and functions of

* Present address: Faculty of Agriculture, Gifu University, Kagamigahara, Gifu. the membranes from the damages of lipid peroxidation. However, few studies have reported whether tocopherols in biomembranes could inhibit lipid peroxidation by ${ }^{1} \mathrm{O}_{2}$.

In this study, lipid peroxidation was performed in isolated spinach chloroplasts by illumination with visible light, and the role of $\alpha$-tocopherol as a free radical scavenger or a ${ }^{1} \mathrm{O}_{2}$ quencher was investigated.

\section{MATERIALS AND METHODS}

Chloroplast preparation. Spinach leaves were homogenized in a medium containing $10 \mathrm{~mm}$ Tris- $\mathrm{HCl}(\mathrm{pH}$ 7.4), $0.45 \mathrm{~m}$ sucrose and $10 \mathrm{~mm} \mathrm{NaCl}$. Pellets which sedimented between 500 to $2000 \times g$ were separated. ${ }^{15)}$ The chloroplasts thus obtained were suspended in two volumes of $50 \%$ glycerol containing $10 \mathrm{~mm}$ Tris- $\mathrm{HCl}$ (pH 7.4) and $10 \mathrm{~mm} \mathrm{NaCl}$, and stored at $-20^{\circ} \mathrm{C}$ until used. ${ }^{16)}$ Chlorophyll concentration was determined by the method of Arnon. ${ }^{17)}$

Photooxidation. The chloroplast preparation was washed twice with a medium containing $175 \mathrm{mM} \mathrm{NaCl}$ and $10 \mathrm{~mm}$ Tris-HCl ( $\mathrm{pH}$ 7.4). The pellet was resuspended in the same medium and was diluted to a suspension containing $0.5 \mathrm{mg}$ of chlorophyll per $\mathrm{ml}$. The suspension was illuminated with a $30 \mathrm{~W}$ tungsten projection lamp (intensity at the sample, $14 \mathrm{~mW} / \mathrm{cm}^{2}=$ $36,000 \operatorname{lux}$ ) at $25^{\circ} \mathrm{C}$ or $4^{\circ} \mathrm{C}$. Additions of free radical scavengers, ${ }^{1} \mathrm{O}_{2}$ quenchers and a hydroxy radical scavenger to the system were made in $0.1 \mathrm{ml}$ of ethanol 
per $0.9 \mathrm{ml}$ of reaction system. The incubations were carried out at $25^{\circ} \mathrm{C}$ for $4 \mathrm{hr}$.

The thiobarbituric acid (TBA) value was determined directly from $1 \mathrm{ml}$ of the incubation mixture by the procedure of Asakawa et al. ${ }^{18)}$ except that $50 \mu \mathrm{l}$ of $10^{-2} \mathrm{M}$ butylated hydroxytoluene and $50 \mu \mathrm{l}$ of $10^{-2} \mathrm{M}$ ethylenediaminetetraacetic acid were added to the assay system to prevent further peroxidation. ${ }^{19)}$

Fluorescence spectral analysis was determined with a Hitachi MPF-4 fluorescence spectrophotometer by the method described by Fletcher et al. ${ }^{20)}$ Quinine sulfate at a concentration of $1 \mu \mathrm{g}$ per ml of $0.1 \mathrm{~N} \mathrm{H}_{2} \mathrm{SO}_{4}$ was used as a standard for fluorescence intensity.

Fatty acid composition of the chloroplast lipids was determined by gas liquid chromatography (GLC) after methanolysis and separation by thin layer chromatography (TLC). ${ }^{21)}$ Heptadecanoic acid was used as an internal standard.

Lipid peroxide analysis. The incubation mixture $(2 \mathrm{ml})$ was reduced by sodium borohydride in $2 \mathrm{ml}$ of methanol. The reduced lipid was extracted by the method of Bligh and Dyer, ${ }^{22)}$ and was hydrogenated by a stream of hydrogen gas. ${ }^{29)}$ The lipid was transesterified with $15 \% \mathrm{BF}_{3}$ in methanol solution. ${ }^{21)}$ The hydroxy fatty acid methyl ester fraction was separated by TLC, benzene-methanol $(95: 5)$ as the solvent system. The compound was silylated and analyzed by gas chromatography-mass spectrometry (GC-MS). The mass chromatography was carried out on a Shimadzu LKB-9000 apparatus equipped with a MSPAC 300 DGB data system according to the method introduced by Terao and Matsushita. ${ }^{24)}$

a-Tocopherol and a-tocopheryl quinone. The extracted lipid was saponified and the tocopherol and tocopheryl quinone fractions were separated by TLC. ${ }^{25)}$ The tocopherol and tocopheryl quinone after silylation were determined by GLC as previously described. ${ }^{14)}$

The $\alpha$-tocopheryl quinone fraction separated by TLC was characterized by GC-MS. The mass chromatography was carried out with an ionizing energy of $22 \mathrm{eV}$ and scanning of the fragment ion at $m / e 293$ and 341 ( $\alpha$-tocopheryl quinone trimethylsilyl derivative) and at $m / e 309$ and 341 ( $\alpha$-tocopheryl quinone epoxide trimethylsilyl derivative). ${ }^{26)}$
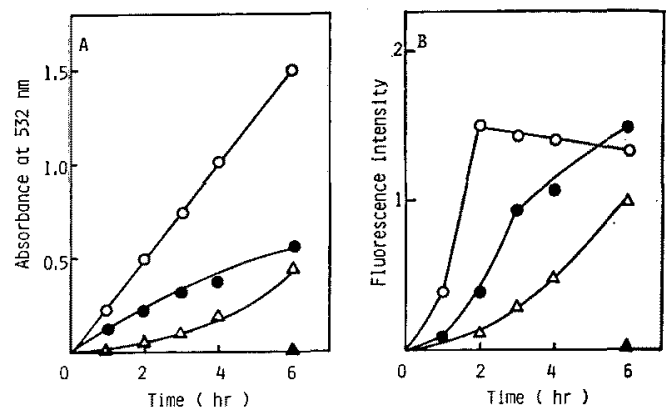

FIG. 1. Formation of TBA Reactants (A) and Fluorescent Substances (B) in Illuminated Chloroplasts.

Chloroplasts suspension ( $0.5 \mathrm{mg}$ of chlorophyll per $\mathrm{ml}$ ) was incubated as described in MeTHODs. $\mathrm{O}-\mathrm{O}$, incubated at $25^{\circ} \mathrm{C}$ in the light; $-\longrightarrow$, incubated at $25^{\circ} \mathrm{C}$ in the dark; $\triangle-\triangle$, incubated at $4^{\circ} \mathrm{C}$ in the light; $\Delta-\Delta$, incubated at $4^{\circ} \mathrm{C}$ in the dark.

\section{RESULTS}

\section{Photooxidation of isolated chloroplasts}

Figure 1 shows the production of TBA reactants and substances with fluorescent properties in illuminated chloroplasts. Formation of TBA reactants was linear with the illumination time at $25^{\circ} \mathrm{C}$. TBA reactants were also formed with illumination at $4^{\circ} \mathrm{C}$. Fluorescent substances resulting from lipid peroxidation had an excitation maximum at $360 \mathrm{~nm}$ and fluorescence maximum at $460 \mathrm{~nm}$. The formation of fluorescent substances showed the same production pattern as that of TBA reactants. The amount of the substances became constant after $2 \mathrm{hr}$ of illumination time at $25^{\circ} \mathrm{C}$.

The amount of fatty acids in the lipid extracts was determined (Table I). The major loss from this photooxidation was in tri-un-

Table I. Fatty Acid Composition of Chloroplast lipids

\begin{tabular}{lcccccc}
\hline & \multicolumn{5}{c}{ Fatty acid (mg/mg of chlorophyll) } \\
\cline { 2 - 7 } & $\mathrm{C}_{14: 0}$ & $\mathrm{C}_{16: 0}$ & $\mathrm{C}_{16: 1}$ & $\mathrm{C}_{16: 3}$ & $\mathrm{C}_{18: 2}$ & $\mathrm{C}_{18: 3}$ \\
\hline $\mathrm{0} \mathrm{hr}$ & 0.02 & 0.12 & 0.06 & 0.15 & 0.07 & 1.04 \\
Illuminated, at $25^{\circ} \mathrm{C}$ & 0.01 & 0.12 & 0.06 & 0.11 & 0.06 & 0.75 \\
at $4^{\circ} \mathrm{C}$ & 0.01 & 0.13 & 0.06 & 0.16 & 0.06 & 0.93 \\
Non-illuminated, at $25^{\circ} \mathrm{C}$ & 0.02 & 0.12 & 0.06 & 0.12 & 0.07 & 0.86 \\
at $4^{\circ} \mathrm{C}$ & 0.01 & 0.13 & 0.07 & 0.17 & 0.07 & 1.05 \\
\hline
\end{tabular}

Incubation was carried out for $6 \mathrm{hr}$. 
Table II. Effect of Free Radical Scayengers, ${ }^{1} \mathrm{O}_{2}$ QUENCHERS AND A HYDROXY Radical

SCAVEnger upon Photooxidation of ChLOROplasts

\begin{tabular}{lc}
\hline \multicolumn{1}{c}{ Addition } & $\begin{array}{c}\text { TBA value } \\
\left(A_{532} / \text { mg of }\right. \\
\text { chlorophyll })\end{array}$ \\
\hline Control & 1.236 \\
Non-illuminated & 0.350 \\
Butylated hydroxytoluene $\left(5 \times 10^{-4} \mathrm{M}\right)$ & 0.164 \\
Hydroquinone $\left(5 \times 10^{-4} \mathrm{M}\right)$ & 0.624 \\
Sodium azide $\left(5 \times 10^{-3} \mathrm{M}\right)$ & 0.552 \\
Tetramethylethylene $\left(1.5 \times 10^{-2} \mathrm{M}\right)$ & 0.759 \\
Dimethyl sulfoxide $\left(5 \times 10^{-3} \mathrm{M}\right)$ & 1.222 \\
\hline
\end{tabular}

The reaction mixture contained chloroplasts ( $0.5 \mathrm{mg}$ of chlorophyll per $\mathrm{ml}$ ) and a inhibitor. Incubation was carried out for $4 \mathrm{hr}$ under illumination provided by a $30 \mathrm{~W}$ projection lamp at $25^{\circ} \mathrm{C}$. TBA value was measured as described in METHODS.

saturated fatty acids, especially linolenic acid.

Table II shows the effect of inhibitors on the photooxidation of chloroplasts at $25^{\circ} \mathrm{C}$. Free radical scavengers, butylated hydroxytoluene and hydroquinone, and ${ }^{1} \mathrm{O}_{2}$ quenchers, sodium azide ${ }^{27 /}$ and tetramethylethylene, ${ }^{28)}$ inhibited lipid peroxidation. On the other hand, the hydroxy radical scavenger, dimethyl sulfoxide, ${ }^{29)}$ did not inhibit peroxidation.

\section{Analysis of lipid peroxidation}

The lipid peroxide in illuminated chloroplasts was analyzed by TLC according to the method described by Kellogg and Friedvich. ${ }^{30}$ No peroxide was detected on the TLC plate. Then the lipid peroxide was measured by the GC-MS method which was used for the analysis of hydroperoxide isomers of oxidized fatty acid methyl esters. ${ }^{24}$ Figure 2 shows the mass chromatogram of the hydroperoxides in illuminated chloroplasts after reduction, hydrogenation and transesterification. The illumination on the chloroplasts was performed at $4^{\circ} \mathrm{C}$ for $6 \mathrm{hr}$. Hydroxy methyl octadecanoate trimethylsilyl derivatives were detected. These products were considered to be reduced products produced from hydroperoxides and their secondary products, keto- and hydroxy-compounds. $^{31)}$ The mass chromatogram shows that the isomers are 9-, 10-, 12-, 13-, 15- and
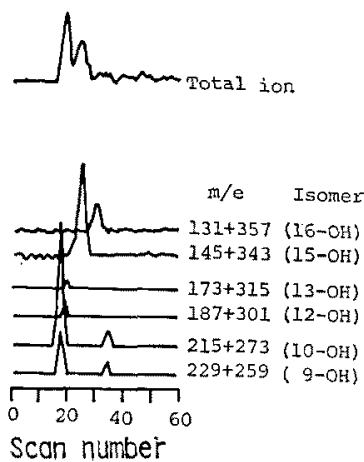

Fig. 2. Mass Chromatogram of the Trimethylsilyl Derivatives of Hydroxy Methyl Octadecanoates.

Chloroplasts suspension was illuminated at $4^{\circ} \mathrm{C}$ for $6 \mathrm{hr}$. The lipid extract was reduced, hydrogenated, transesterified and silylated for $\mathrm{GC}-\mathrm{MS}$ analysis.

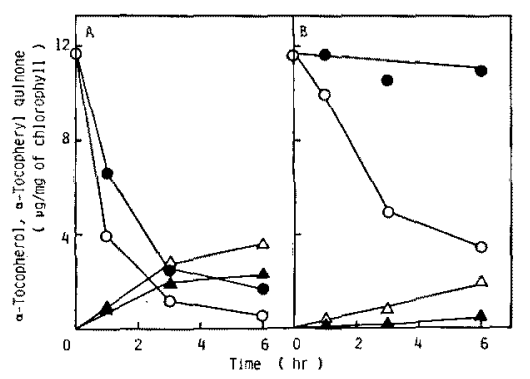

FIG. 3. Changes of $\alpha$-Tocopherol and $\alpha$-Tocopheryl Quinone in the Illuminated Chloroplasts.

Chloroplast suspension was illuminated at $25^{\circ} \mathrm{C}$ (A) and $4^{\circ} \mathrm{C}(\mathrm{B})$.

$\mathrm{O}-\mathrm{O}, \alpha$-tocopherol, incubated in the light; $\alpha$-tocopherol, incubated in the dark; $\triangle-\triangle, \alpha$-tocopheryl quinone, incubated in the light; $\Lambda-\Lambda, \alpha$-tocopheryl quinone, incubated in the dark.

16-hydroxy methyl octadecanoate trimethylsilyl derivatives from the fragment ion peaks based on the $\alpha$-cleavage of the trimethylsilyloxy group. Among them, 10- and 15-hydroxy methyl octadecanoates are the characteristic products of ${ }^{1} \mathrm{O}_{2}$ oxidation. ${ }^{24)}$ During incubation time, the amount of hydroxy methyl octadecanoates in the chloroplasts was constant below $10 \mu \mathrm{g}$ per mg of chlorophyll and accumulation of the compounds was not observed in the incubation mixture both 4 and $25^{\circ} \mathrm{C}$.

$\alpha$-Tocopherol and $\alpha$-tocopheryl quinone in the chloroplasts 


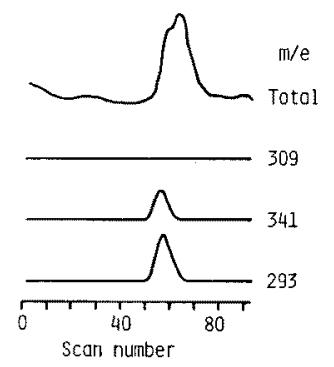

FIG. 4. Mass Chromatogram of the Trimethylsilyl Derivative of $\alpha$-Tocopheryl Quinone Fraction.

Chloroplast suspension was illuminated at $25^{\circ} \mathrm{C}$ for $6 \mathrm{hr}$. The lipid extract was saponified and the $\alpha-$ tocopheryl quinone fraction separated by TLC was silylated for GC-MS analysis.

Figure 3 shows quantitative changes of $\alpha$ tocopherol and $\alpha$-tocopheryl quinone, the oxidation product of $\alpha$-tocopherol, in the chloroplasts. At $25^{\circ} \mathrm{C}, \alpha$-tocopherol in the chloroplasts decreased rapidly with incubation time, and $\alpha$-tocopheryl quinone was produced. When the suspension was incubated at $4^{\circ} \mathrm{C}$, the amount of $\alpha$-tocopherol in the illuminated chloroplasts also decreased, but the amount of $\alpha$-tocopherol under dark incubation was constant.

The oxidation product of $\alpha$-tocopherol in the illuminated chloroplasts was analyzed by GC-MS. Figure 4 shows the mass chromatogram of the oxidation product of $\alpha$-tocopherol after silylation. The chloroplast suspension was illuminated at $25^{\circ} \mathrm{C}$ for $6 \mathrm{hr}$. From the fragment ion peaks at $m / e 293$ and $341, \alpha$-tocopheryl quinone trimethylsilyl derivative was identified as the oxidation product. However, $\alpha$-tocopheryl quinone epoxide, which was the ${ }^{1} \mathrm{O}_{2}$ oxidation product of $\alpha$-tocopherol, ${ }^{32}$ was not detected. In every experiment, only $\alpha$ tocopheryl quinone was detected in the chloroplasts as the oxidation product of $\alpha$-tocopherol.

\section{DISCUSSION}

Lipid peroxidation in the chloroplasts has been considered to be induced by the action of ${ }^{1} \mathrm{O}_{2}$ which was generated by illumination, and the photoinactivation and photodestruction of chloroplasts occurred., ${ }^{8,9)}$ The ${ }^{1} \mathrm{O}_{2}$ quenchers and free radical scavengers inhibited the peroxidation of the illuminated chloroplasts (Table II). Moreover, hydroxy methyl octadecanoate isomers, which were the reduced and hydrogenated products of lipid hydroperoxides, were detected by mass chromatography (Fig. 2). The mass chromatogram showed that the 10- and 15-isomers, characteristic products formed by the photooxidation of methyl linolenate, ${ }^{24)}$ occupied a large amount of the products. Therefore, ${ }^{1} \mathrm{O}_{2}$ and free radicals may be responsible for the photooxidation of chloroplasts.

Hydroperoxides have not been detected in living tissues and the formation and existence of free radicals in biological systems has been widely accepted..$^{33)}$ Tappel $^{34}$ proposed that hydroperoxides underwent homolytic decomposition in vivo through catalytic action of metals yielding free radicals that perpetuated the reaction with cellular constituents. Lipid hydroperoxide in illuminated chloroplast extracts was not detected by TLC analysis. And the mass chromatographic data showed that the amount of hydroperoxides did not increase during incubation time both at 4 and $25^{\circ} \mathrm{C}$. The results indicate that the lipid hydroperoxide formed by photooxidation of chloroplasts may be decomposed immediately by free radical reaction.

The protective role of tocopherols against lipid peroxidation was believed to involve a free radical scavenge ${ }^{11,12}$ and a ${ }^{1} \mathrm{O}_{2}$ quencher. ${ }^{13,14}$ The autoxidation products of tocopherols were quinone, dimer and so on, ${ }^{35)}$ while the photooxidation products of tocopherols were quinone epoxide and quinone. ${ }^{32)}$ The amount of $\alpha$-tocopherol in chloroplasts decreased with the formation of TBA reactants and fluorescent substances, and $\alpha$-tocopheryl quinone was formed as an oxidation product of $\alpha$-tocopherol (Fig. 3). The major product formed by the photooxidation of $\alpha$-tocopherol in chloroplasts was $\alpha$-tocopheryl quinone. No $\alpha$-tocopheryl quinone epoxide was detected in the illuminated chloroplasts (Fig. 4). Carotenoids occur in chloroplast lamellae. The quenching rate of ${ }^{1} \mathrm{O}_{2}$ by carotenoids is higher 
by about two orders of magnitude than that of $\alpha$-tocopherol. ${ }^{36)} \quad$ Therefore, carotenoids in chloroplasts are considered to play a role in quenching ${ }^{1} \mathrm{O}_{2}$. But carotenoids are easily destroyed by the free radical products of lipid peroxidation. $\alpha$-Tocopherol can scavenge the free radicals to form $\alpha$-tocopheryl quinone as the oxidation product. Therefore, $\alpha$-tocopherol in chloroplasts may act to scavenge free radicals rather than quench ${ }^{1} \mathrm{O}_{2}$ to protect chloroplast function from lipid peroxidation.

\section{REFERENCES}

1) C. S. Foote, Science, 162, 963 (1968).

2) H. R. Rawls and P. J. Van Santen, J. Am. Oil Chem. Soc., 47, 121 (1970).

3) M. M. King, E. K. Lai and P. B. McCay, J. Biol. Chem., 250, 6496 (1975).

4) C. S. Foote, Y. G. Ching and R. W. Denny, $J$. Am. Chem. Soc., 92, S216 (1970).

5) J. Terao and S. Matsushita, Agric. Biol. Chem., 41, 2467 (1977).

6) A. T. James and B. W. Nichols, Nature, 210, 372 (1966).

7) C. F. Allen, P. Good, H. F. Davis, P. Chisum and S. D. Fowler, J. Am. Oil Chem. Soc., 43, 223 (1966).

8) R. L. Heath and L. Packer, Arch. Biochem. Biophys., 125, 189 (1968); idem, ibid., 125, 850 (1968).

9) U. Takahama and M. Nishimura, Plant Cell Physiol., 16, 737 (1975); idem., ibid., 17, 111 (1976).

10) C. Bucke, Phytochemistry, 7, 111 (1976).

11) A. L. Tappel, Ann. N. Y. Acad. Sci., 203, 12 (1972).

12) J. Green, ibid., 203, 29 (1972).

13) S. R. Fahrenholtz, F. H. Doleiden, A. M. Trozzolo and A. A. Lamola, Photochem. Photobiol., 20, 505 (1974).

14) R. Yamauchi and S. Matsushita, Agric. Biol.
Chem., 41, 1425 (1977).

15) A. Koiwai and T. Kisaki, Plant Cell Physiol., 17, 1199 (1976).

16) K. Asada and M. Takahashi, ibid., 12, 709 (1971).

17) D. I. Arnon, Plant Physiol., 24, 1 (1949).

18) T. Asakawa, Y. Nomura and S. Matsushita, Yukagaku, 24, 481 (1975).

19) O. Shimada and H. Yasuda, Biochin. Biophys. Acta, 489, 163 (1977).

20) B. L. Fletcher, C. J. Dillard and A. L. Tappel, Anal. Biochem., 52, 1 (1973).

21) F. E. Luddy, J. Am. Oil Chem. Soc., 45, 549 (1968).

22) E. G. Bligh and W. J. Dyer, Can. J. Biochem. Physiol, 37, 911 (1959).

23) J. Terao and S. Matsushita, Agric. Biol. Chem., 39, 2027 (1975).

24) J. Terao and S. Matsushita, The Abstracts of Papers, 5th International Congress of Food Science and Technology, Kyoto, 1978, p. 202.

25) T. Tsugo, K. Yamauchi and C. Kanno, Nippon Nögeikagaku Kaishi, 42, 367 (1968):

26) R. Yamauchi and S. Matsushita, Agric. Biol. Chem., 43, 2151 (1979).

27) N. Hasty, P. B. Merkel, P. Radlick and D. R. Kearns, Tetrahedron Lett., 1972, 49.

28) T. Wilson, J. Am. Chem. Soc., 90, 6233 (1968).

29) A. I. Cederbaum, E. Dicker, E. Rubin and G. Cohen, Biochem. Biophys. Res. Comm., 78, 1254 (1977).

30) E.W. Kellogg, III and I. Fridovich, J. Biol. Chem., 250, 8812 (1975).

31) H. W. Gardner, R. Kleiman and D. Weisleder, Lipids, 9, 696 (1974)

32) G. W. Grams and G. E. Inglett, Lipids, 7, 442 (1972).

33) E. D. Willis, Biochem. J., 99, 667 (1966).

34) A. L. Tappel, Fed. Proc., 32, 1870 (1973).

35) M. Fujimaki, K. Kanamaru, T. Kurata and $O$. Igarashi, Agric. Biol. Chem., 34, 1781 (1970).

36) C. S. Foote and R. W. Denny, J. Am. Chem. Soc., 90, 6233 (1968). 